\title{
Arterial switch operation with a single coronary artery
}

\author{
Albertus M. Scheule, MD ${ }^{\mathrm{a}^{*}}$ \\ David Zurakowski, $\mathrm{PhD}^{\mathrm{b}}$ \\ Elizabeth D. Blume, MD ${ }^{\mathrm{c}}$ \\ Christof Stamm, MD ${ }^{\mathrm{a}}$ \\ Pedro J. del Nido, MD ${ }^{a}$ \\ John E. Mayer, Jr, MD ${ }^{\mathrm{a}}$ \\ Richard A. Jonas, MD
}

From the Departments of Cardiac Surgery, Cardiology, ${ }^{\mathrm{c}}$ and Biostatistics, ${ }^{\mathrm{b}}$ Children's Hospital, Harvard Medical School, Boston, Mass.

Received for publication April 9, 2001; revisions requested May 17, 2001; revisions received June 13, 2001; accepted for publication June 18, 2001.

Address for reprints: Richard A. Jonas, MD, Department of Cardiac Surgery, Children's Hospital Boston, 300 Longwood Ave, Boston, MA 02115 (E-mail: richard.jonas@tch.harvard.edu).

*Evarts A. Graham Traveling Fellow, 20002001.

J Thorac Cardiovasc Surg 2002;123: 1164-72

Copyright () 2002 by The American Association for Thoracic Surgery

0022-5223/2002 \$35.00+0 $\quad \mathbf{1 2 / 1 / 1 1 8 0 4 7}$

doi:10.1067/mtc.2002.118047
Objective: Our purpose was to evaluate the impact of coronary pattern on survival and reintervention in patients who underwent the arterial switch operation with a single coronary artery.

Methods: We conducted a retrospective analysis of 53 patients with a single coronary artery who underwent the arterial switch operation between 1983 and 2000 at Children's Hospital Boston. Recent follow-up information was obtained for 40 of the 46 long-term survivors (mean follow-up $7.3 \pm 4.5$ years).

Results: Thirty-five patients had a single right coronary artery, with the left coronary artery posterior to the pulmonary artery in 27 . Eighteen patients had a single left coronary artery ( 16 with the right coronary artery anterior to the aorta). Six of 7 total patients who died had a single right coronary artery; all died before 1992. There were 5 early deaths, all with a single right coronary artery, with 4 deaths due to coronary malperfusion. Survivals for all patients were $91 \%$ at 6 months and $87 \%$ at 1,5 , and 10 years after the arterial switch operation. Survival figures were lower for patients having a single right ostium with the left main coronary artery posterior to the pulmonary artery compared with all other subtypes $(P=.02$, log-rank test). Seven patients had reintervention, 4 because of right ventricular outflow tract obstruction, 1 for heart transplantation, 1 for mitral valve repair and 1 for pacemaker implantation. Freedom from reintervention for all patients was $96 \%$ at 6 months, $92 \%$ at 1 year, $86 \%$ at 5 years, and $82 \%$ at 10 years after the arterial switch operation, with lower rates for patients having a single left ostium with the right coronary artery anterior to the aorta $(P=.0003, \log$-rank test).

Conclusions: In the current era, the arterial switch operation with a single coronary artery can be performed safely irrespective of the coronary anatomy. Risk of reintervention is higher in patients having a single left ostium with the right coronary artery anterior to the aorta.

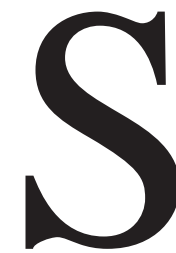

ingle coronary artery (CA) has been reported by several centers, including a multicenter study of the Congenital Heart Surgeons Society, ${ }^{1-4}$ to be an independent risk factor for increased mortality for patients undergoing an arterial switch operation (ASO). Wernovsky and coworkers ${ }^{5}$ found that a single right CA pattern was a risk factor for increased operative mortality in a consecutive series of patients operated on between 1983 and 1992 at Children's Hospital Boston. In a more recent study from our institution, focusing on patients operated on between 1993 and 1997, Blume and colleagues ${ }^{6}$ found that a single CA was not a risk factor for increased early mortality. Nevertheless, the rarer coronary branching patterns, including single $\mathrm{CA}$, represent a considerably greater technical challenge to the surgeon treating congenital cardiac disease. We therefore studied the outcome of patients with 
transposition of the great arteries (TGA) or double-outlet right ventricle (DORV) and single CA patterns undergoing the ASO at Children's Hospital to evaluate the impact of different single CA patterns on mortality. Risk factors having significant impact on patient outcome were analyzed.

\section{Patients and Methods}

Patients were identified by a search of the clinical database of the Cardiovascular Program at Children's Hospital Boston. All patients who underwent the ASO for TGA or DORV between January 1, 1983, and June 30, 2000, were included. Hospital charts, echocardiographic and cardiac catheterization data, and operative reports were reviewed. The follow-up status was determined by a review of the chart and an inquiry letter or a telephone interview with the patient's parents. Outcomes measured were mortality, exercise limitation, and the need for any intervention or reoperation. Approval for this study was obtained by the Institutional Review Board at Children's Hospital.

\section{Data Collection}

Patient demographic variables included age at operation, weight, and body surface area at birth. Other variables recorded were presence or absence of a ventricular septal defect (VSD), relative position of the great arteries, and aortic arch anomalies including interruption, coarctation, or arch hypoplasia. CA anatomy was determined by echocardiography and catheterization and was verified by direct visualization at the time of the operation. Preoperative data included balloon atrial septostomy, prior cardiac surgical procedures, and the use of extracorporeal support. Intraoperative procedural data recorded included surgical technique such as the Lecompte maneuver, aortic arch repair, double switch, and takedown of prior Blalock-Taussig shunt and pulmonary artery (PA) band. Total cardiopulmonary bypass time, crossclamp time, revision of the coronary anastomosis, and delayed sternal closure were recorded. Postoperative variables included time of mechanical ventilation, days in the cardiac intensive care unit (ICU), and postoperative hospital stay. Mortality was defined as death within 30 days of ASO or before discharge.

\section{Follow-up}

A formal cross-sectional follow-up was conducted between July and November 2000. An inquiry letter was sent to the parents of each patient not known to be dead. For parents who did not respond within 3 weeks, further attempts were made to locate and interview them via telephone. We used a commercially based search company (US search.com, Los Angeles, Calif) to locate patients who could not otherwise be found. This search confirmed the vital status of each patient. Recent information was obtained on $40(87 \%)$ of the 46 long-term survivors. Among the 6 patients who could not be contacted, 4 had at least 2 years of follow-up.

\section{Statistical Analysis}

Continuous data including age, follow-up, crossclamp time, total pump time, mechanical ventilation time, length of time in the cardiac ICU, and postoperative hospital stay were tested for normality by the Kolmogorov-Smirnov statistic, and those variables not following a normal distribution (age, ventilation time, ICU and hospital stay) were expressed in terms of the median and interquartile range. Other variables, including follow-up, were presented in terms of the mean and standard deviation (SD). Actuarial survival and freedom from reintervention were estimated by means of the Kaplan-Meier product-limit method with curves compared by the log-rank test. ${ }^{7}$ Greenwood's formula was applied to calculate $95 \%$ confidence intervals (CI) around the survival and freedom from reintervention curves, with error bars represented by the lower 95\% CI for visual presentation in the figures. Since all deaths occurred within the first 7 months after ASO, logistic regression was used in the risk factor analysis of early and total mortality. The likelihood ratio test was used to assess significance of the variables tested and a backward stepwise procedure was applied with $P<.05$ used for retention in the final models. ${ }^{8}$ The covariates tested included age at operation, sex, birth weight, presence of a VSD, aortic arch obstruction, Taussig-Bing type of DORV, position of the great arteries, single CA pattern, prior PA banding, balloon atrial septostomy, Lecompte maneuver, revision of the coronary anastomosis, delayed sternal closure, crossclamp and total pump time, duration of mechanical ventilation, time in the ICU, postoperative hospital stay, and year of operation. Variables having a $P<.2$ in the univariable analysis qualified as candidates in the multivariable models. For reintervention, the Cox proportional hazards regression model was used to adjust for possible confounding and to identify variables independently associated with reintervention. The 3 operative deaths were excluded from the analysis of reintervention, and a backward stepwise hierarchical procedure was used to determine variables in the final model. ${ }^{9}$ The risk ratio and $95 \%$ CI were reported for significant multivariable risk factors. Statistical analysis was performed with SPSS version 10.1 and SigmaPlot version 4.0 software (SPSS, Inc, Chicago, Ill).

\section{Results}

Between January 1983 and June 2000, 844 patients underwent ASO at our institution, of whom 53 (6.3\%) had a single CA pattern. The specific CA anatomy is illustrated in Figure 1. Thirty-seven $(70 \%)$ were male. Median age at operation was 10 days (interquartile range $=2-62$ days). Mean follow-up of the survivors was 7.3 years $(\mathrm{SD}=4.5$ years). Twenty-nine operations have been performed since 1990. Characteristics of all 53 patients in the study population are presented in Table 1. Other associated lesions included left ventricular outflow tract obstruction $(\mathrm{n}=4)$, abnormal pulmonary valve structure with pulmonary stenosis $(\mathrm{n}=3)$, total atrioventricular canal $(\mathrm{n}=1)$, abnormal tricuspid valve attachments $(n=1)$, interrupted inferior vena cava $(\mathrm{n}=1)$, and left atrial supravalvular mitral membrane $(\mathrm{n}=1)$. One patient required extracorporeal membrane oxygenation preoperatively. There were 5 patients (9\%) with a Taussig-Bing anomaly, defined as a DORV with a subpulmonary VSD, mitral-to-pulmonary valve fibrous discontinuity, and side-by-side position of the great vessels. ${ }^{10}$ Two patients had L-loop (corrected) TGA with VSD and underwent a double switch procedure. The position of the great arteries (aorta in relation to the PA) was 


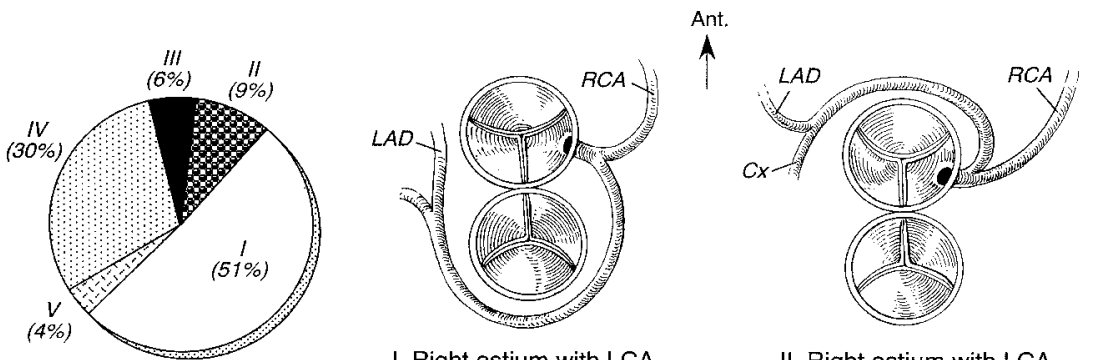

I. Right ostium with LCA posterior to the PA

II. Right ostium with LCA anterior to the aorta

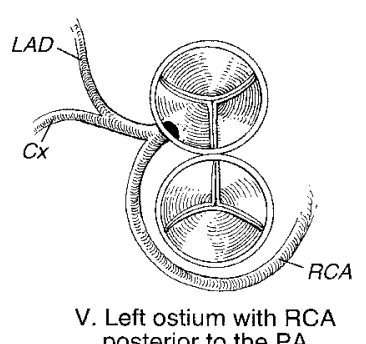

Figure 1. Descriptive classification of single CA anatomy in the study population. The graph shows the distribution of the single CA pattern. Cx, Circumflex artery; $L A D$, left anterior descending artery; $P A$, pulmonary artery; $R C A$, right coronary artery.

TABLE 1. Characteristics of patients with a single CA pattern $(n=53)$

\begin{tabular}{lc}
\hline Characteristic & No. (\%) \\
\hline Age in days at surgery, median, IOR & $10,2-62$ \\
Sex & $37(70)$ \\
Male & $16(30)$ \\
Female & $3460 \pm 620$ \\
Birth weight in grams, mean \pm SD & $33(62)$ \\
VSD & $3(6)$ \\
Aortic arch obstruction & $5(9)$ \\
Taussig-Bing type of DORV & $15(28)$ \\
Position of the great arteries (aorta in relation to PA) & $32(60)$ \\
Side-by-side & $3(6)$ \\
Anterior and rightward & $3(6)$ \\
Anterior and leftward & $27(51)$ \\
Direct anterior & $16(30)$ \\
Single CA pattern & $5(9)$ \\
Right ostium with left CA posterior to the PA & $3(6)$ \\
Left ostium with right CA anterior to the aorta & $2(4)$ \\
Right ostium with left CA anterior to the aorta & $24(45)$ \\
Right ostium with left CA between the great arteries & $29(55)$ \\
Left ostium with left CA posterior to the PA & \\
Year of surgery & \\
1983-1990 &
\end{tabular}

IQR, Interquartile range; $S D$, standard deviation; $V S D$, ventricular septal defect; $D O R V$, double-outlet right ventricle; $P A$, pulmonary artery; $C A$, coronary artery. Percentages are shown in parentheses.

anterior and rightward in $60 \%$ of patients, side by side in $28 \%$, anterior and leftward in $6 \%$, and direct anterior in $6 \%$. Thirty-eight (72\%) patients underwent preoperative balloon atrial septostomy, either in the ICU under echocardiographic guidance or in the cardiac catheterization labora- tory. Revision of the coronary anastomosis at the time of ASO was required in $7(13 \%)$ patients intraoperatively because of myocardial ischemia. Six (11\%) of the 53 patients in our review had a prior PA band. All patients with a prior PA band were operated on elsewhere before being 
referred to Boston. The 2 patients with L-loop TGA had an additional Blalock-Taussig shunt. Operative and postoperative variables are summarized in Table 2.

\section{Patient Survival}

Five (9\%) of the 53 patients with a single CA pattern died early and 2 died late. Six of the 7 patients who died had a single right ostium with the left CA posterior to the PA. Of the 5 early deaths, 3 occurred on the day of surgery, 1 occurred 6 weeks postoperatively, and 1 occurred 2 months after ASO as a result of sepsis. Autopsies revealed that except in the patient who died of sepsis, all deaths were due to coronary malperfusion. Six months postoperatively, 2 patients died suddenly ( 1 was known to have severe pulmonary hypertension and the other had no apparent symptoms). Since July 1991, no patient with a single CA pattern has died. However, 1 patient was placed on extracorporeal membrane oxygenation and underwent successful transplantation 7 days after a double switch procedure. The biannual number of ASO procedures and the number of patients who died are shown in Figure 2.

\section{Actuarial Survivals}

Kaplan-Meier estimated survivals (95\% CI) for all patients with single CA pattern were $91 \%$ (84\%-98\%) at 6 months and $87 \%(79 \%-95 \%)$ at 1,5 , and 10 years after ASO (Figure 3). Survival was lower in patients having a single right ostium with the left CA posterior to the PA compared with all other subtypes $(P=.02$, log-rank test) (Figure 4). Estimated survivals were 78\% (66\%-90\%) and 96\% (92\%$100 \%$ ) for patients having a single right ostium with the left CA posterior to the PA compared with all other CA patterns, respectively, at 1 year after ASO and thereafter.

\section{Risk Factors for Mortality}

Risk factors for mortality are shown in Table 3. For early and overall mortality, stepwise logistic regression revealed 3 independent risk factors: earlier year of surgery, CA pattern (single right ostium with the left CA posterior to the PA), and revision of CA anastomosis. Since 1983, the estimated risk of mortality has decreased $30 \%$ each year (odds ratio $=0.7$ ). Patients with a single right ostium with the left CA posterior to the PA were estimated to have an approximately 7- to 8-fold increased risk of death after ASO compared with other single CA patterns. Patients requiring revision of the CA anastomosis had a 4- to 7-fold increased risk of mortality. For early death, the multivariable analysis estimated 5\% increased risk for each additional minute of crossclamp time. For overall mortality, patients with a sideby-side position of the great arteries had a 6-fold increased risk of death. As indicated in Table 3, none of the other variables considered was associated with the need for rein-
TABLE 2. Operative and postoperative variables

\begin{tabular}{lr}
\hline Variable & No. (\%) \\
\hline Prior PA banding, ${ }^{*}$ no. (\%) & $6(11)$ \\
Balloon atrial septostomy, no. (\%) & $38(72)$ \\
Lecompte maneuver, no. (\%) & $40(76)$ \\
Revision of coronary anastomosis, no. (\%) & $7(13)$ \\
Delayed sternal closure, no. (\%) & $16(30)$ \\
Cross clamp time, min & $85 \pm 26$ \\
Total pump time, min & $160 \pm 60$ \\
Mechanical ventilation, days & $4(3-6)$ \\
Length of stay in the ICU, days & $6(4-8)$ \\
Length of postoperative hospital stay, days & $10(7-22)$
\end{tabular}

$P A$, Pulmonary artery; ICU, cardiac intensive care unit. Plus-minus values represent the mean and standard deviation. Days are represented as median with the interquartile range shown in parentheses.

* Two patients had a PA band and a Blalock-Taussig shunt.

tervention in the univariable or multivariable analyses (all $P>$.2).

\section{Reintervention}

Seven patients had reintervention, 4 because of right ventricular outflow tract obstruction, 1 for heart transplantation, 1 for mitral valve repair, and 1 for pacemaker implantation. In 6 of the 7 reinterventions, the CA pattern was a single left ostium with the right $\mathrm{CA}$ anterior to the aorta.

\section{Actuarial Freedom From Reintervention Rates}

Kaplan-Meier estimated freedom from reintervention rates (95\% CI) for all patients, excluding the 3 operative deaths, were $96 \%(92 \%-100 \%)$ at 6 months, $92 \%(86 \%-98 \%)$ at 1 year, $86 \%(78 \%-94 \%)$ at 5 years, and $82 \%(74 \%-90 \%)$ at 10 years after ASO (Figure 3). Reintervention rates were higher in patients having a single left ostium with the right $\mathrm{CA}$ anterior to the aorta compared with all other CA patterns $(P=.0003$, log-rank test) (Figure 5$)$. Freedom from reintervention rates were $66 \%(50 \%-82 \%)$ and $95 \%(90 \%$ $100 \%$ ) for patients having a single left ostium with the right $\mathrm{CA}$ anterior to the aorta compared with all other CA patterns, respectively, at 5 years after ASO.

\section{Reintervention for Right Ventricular Outflow Obstruction}

Considering reintervention for right ventricular outflow tract obstruction, the Kaplan-Meier freedom from reintervention rates for all single CA patterns were 98\% (96\%$100 \%)$ at 6 months and 1 year, $92 \%(86 \%-98 \%)$ at 5 years, and $88 \%(81 \%-95 \%)$ at 10 years. Reintervention rates were higher in patients having a single left ostium with the right CA anterior to the aorta compared with all other CA patterns $(P=.013$, long-rank test). Specifically, freedom from reintervention rates $(95 \% \mathrm{CI})$ were $82 \%(72 \%-92 \%)$ and 96\% (90\%-100\%) for patients having a single left ostium 


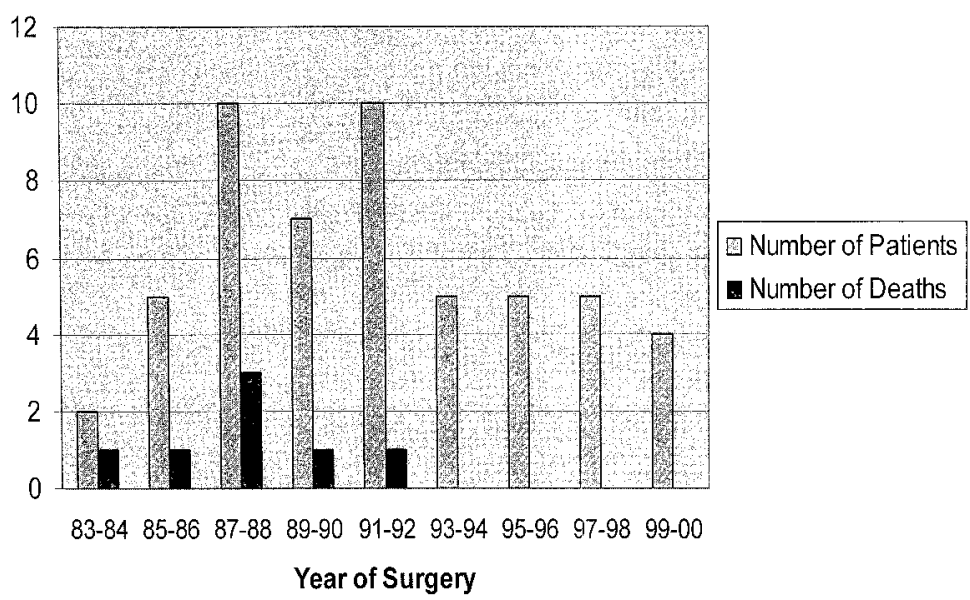

Figure 2. Distribution of the numbers of patients who underwent the ASO and the corresponding number of patients who died according to the year of surgery. A significant decline was observed in the percentage of deaths since $1983\left(P=.014, \chi^{2}\right.$ test of trend).

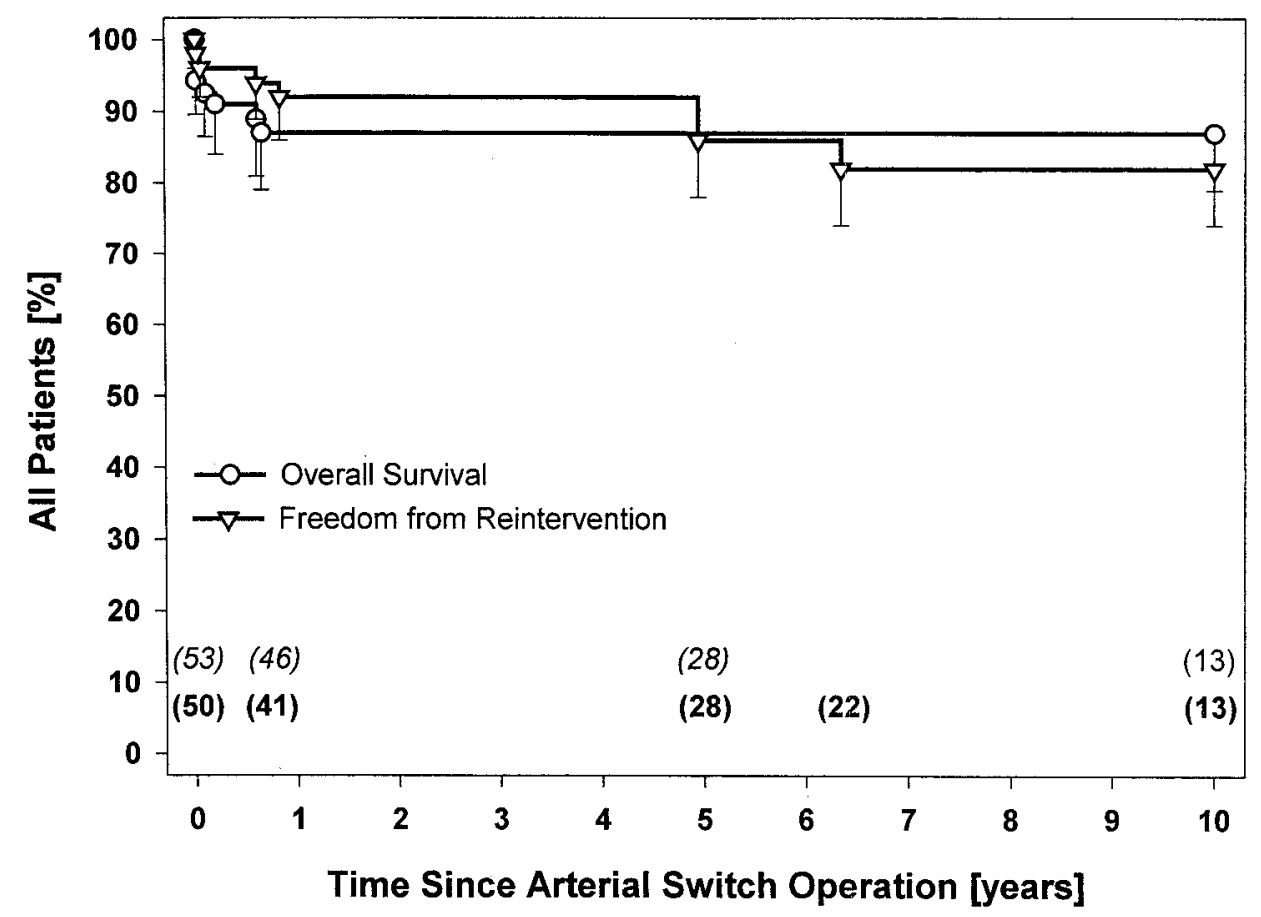

Figure 3. Kaplan-Meier estimated overall survival and freedom from reintervention for all patients through 10 years of follow-up after the ASO. Error bars indicate the lower $95 \% \mathrm{Cl}$. Numbers shown in parentheses in italics represent patients who are alive and still being followed up, and the values in boldface represent the numbers of patients free from reintervention in the follow-up period.

with the right $\mathrm{CA}$ anterior to the aorta compared with all other CA patterns, respectively, at 5 years after ASO.

\section{Risk Factors for Reintervention}

Risk factors for reintervention are shown in Table 4. Age at operation, presence of a Taussig-Bing DORV, position of the great arteries, CA pattern, and year of operation were considered as candidates in the multivariable Cox regression model. Of these 5 variables, CA pattern was the only significant independent risk factor associated with reintervention $(P<.001)$. Need for reintervention was 16 -fold higher each year for patients having a single left ostium with the right $\mathrm{CA}$ anterior to the aorta (risk ratio $=16.5,95 \%$ $\mathrm{CI}=2.8-38.9)$. As indicated in Table 4, none of the other 


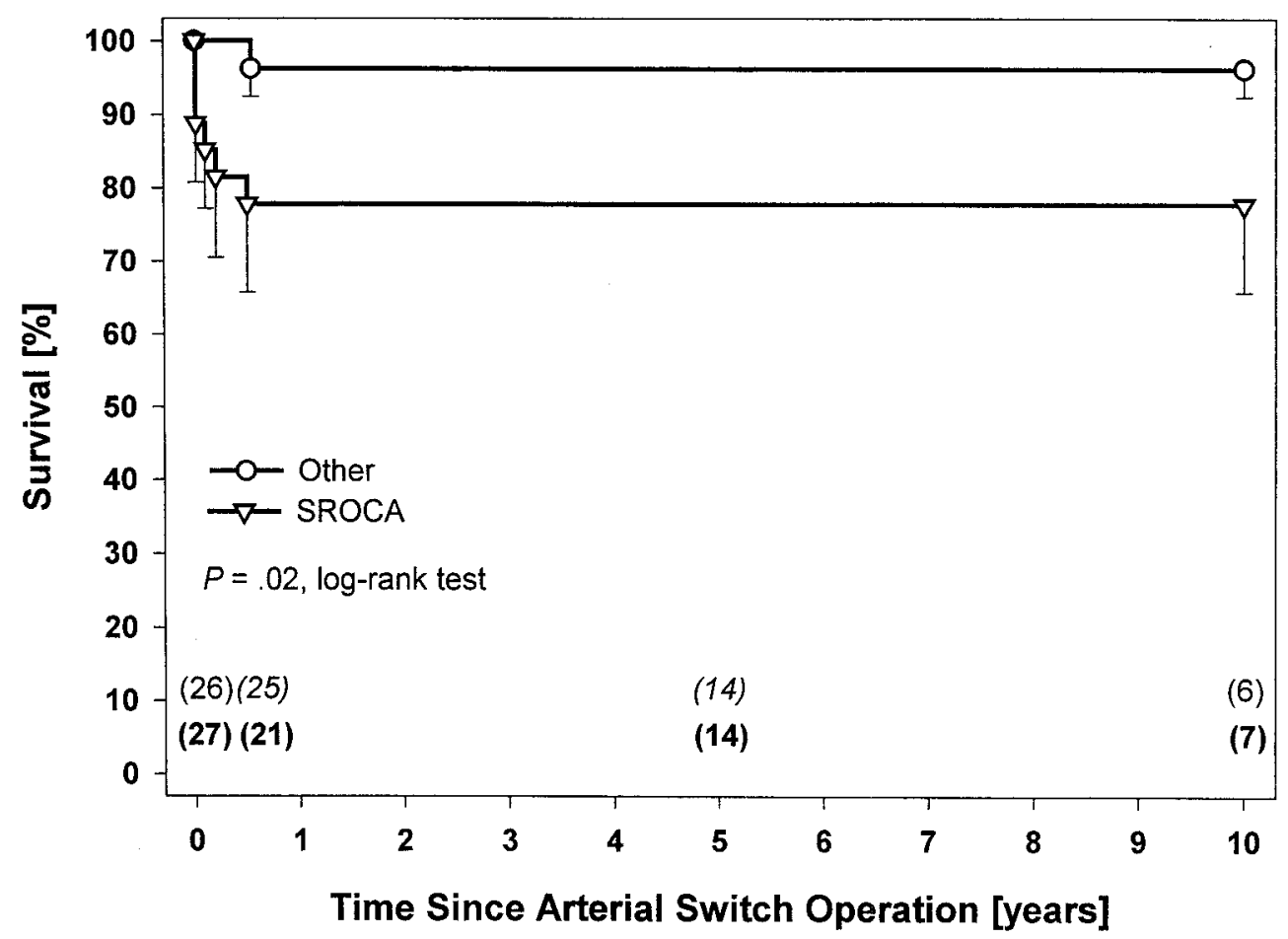

Figure 4. Kaplan-Meier overall survival according to single CA pattern $(P=.02$, log-rank test) for 10 years of follow-up after ASO. Error bars indicate the lower $95 \% \mathrm{CI}$. Number of patients at risk shown in parentheses in boldface represent patients having a single right ostium with the left CA (SROCA) posterior to the PA (see Figure 1, II) compared with patients with other CA patterns shown in italics.

variables was associated with the need for reintervention in the univariable or multivariable analyses (all $P>.2$ ). The same set of variables was tested for possible statistical significance when considering reintervention for right ventricular outflow tract obstruction as the outcome. Multivariable Cox regression revealed that the CA pattern was the only significant independent risk factor $(P=.01)$. Need for reintervention was estimated to be 10 -fold higher each year for patients having a single left ostium with the right CA anterior to the aorta (risk ratio $=10.0,95 \%$ CI $=2.4-$ 47.5). None of the other variables was associated with the need for reintervention in the univariable or multivariable analyses (all $P>.2$ ).

Exercise Tolerance, Medications, and Heart Rhythm Thirty-eight (95\%) of 40 patients having formal crosssectional follow-up reported excellent exercise tolerance with no limitations. Two patients reported limited exercise tolerance, due to hip dysplasia in 1 patient and to severe neurologic deficit in the other. This patient had a cardiac arrest before the ASO. Except for the 1 patient with the neurologic deficit who receives anticonvulsant medication, all other patients are free of medication and all are reported to have sinus rhythm.

\section{Discussion}

The results of the ASO have improved considerably during the past 15 years. In a multi-institutional report from the Congenital Heart Surgeons Society, ${ }^{11}$ overall survival of 187 patients with D-TGA who were operated on between January 1985 and June 1986 was low with only $81 \%$ of patients surviving at 1 year. In the current era, patient survivals at large-volume institutions exceed 92\% 1 year after ASO. 3,12,13

For ASO in patients with TGA and single CA pattern this trend is even more distinct. Wernovsky and Sanders ${ }^{12}$ undertook an analysis of 470 patients who had undergone the ASO at Children's Hospital Boston between 1983 and 1991. Six $(29 \%)$ of 21 patients with a single right CA pattern died after the ASO. In a 1999 report from the same institution, Blume and coworkers ${ }^{6}$ reviewed 223 patients who underwent an ASO between January 1992 and December 1996. In this series, no patient with a single CA pattern died. Our analysis revealed that at Children's Hospital Boston, since 1983, the yearly risk for mortality in patients with ASO and single CA pattern decreased by $30 \%$. A similar experience has been described recently by Shukla, Freedom, and Black. ${ }^{14}$ Although the mortality was $38 \%$ in patients with 
TABLE 3. Risk factors for early and overall mortality

\begin{tabular}{|c|c|c|c|c|}
\hline \multirow[b]{3}{*}{ Outcome of interest } & \multicolumn{4}{|c|}{ Univariable and multivariable logistic regression } \\
\hline & \multirow{2}{*}{$\frac{\text { Univariable }^{*}}{P \text { value }}$} & \multicolumn{3}{|c|}{ Multivariable analysis } \\
\hline & & Odds ratio & $95 \% \mathrm{Cl}$ & $P$ value \\
\hline \multicolumn{5}{|l|}{ Early mortality } \\
\hline Cross clamp time, min & .05 & 1.05 & $1.02-1.08$ & $<.01$ \\
\hline Total pump time, min & .03 & & & .8 \\
\hline Position of the great arteriest & .04 & & & .14 \\
\hline Revision of coronary anastomosis & .01 & 7.0 & 1.8-15.4 & .01 \\
\hline Coronary artery pattern $\ddagger$ & $<.01$ & 8.5 & $2.0-30.8$ & $<.01$ \\
\hline Year of surgery & $<.01$ & 0.7 & $0.5-0.9$ & $<.01$ \\
\hline \multicolumn{5}{|l|}{ Overall mortality (early or late) } \\
\hline Prior PA banding & .12 & & & .75 \\
\hline Total pump time, min & .07 & & & .15 \\
\hline Position of the great arteries* & .05 & 6.0 & $2.2-17.8$ & .03 \\
\hline Revision of coronary anastomosis & .02 & 4.2 & $1.3-8.8$ & .02 \\
\hline Coronary artery pattern $\ddagger$ & .02 & 7.1 & $2.1-24.6$ & $<.01$ \\
\hline Year of surgery & $<.01$ & 0.7 & $0.6-0.9$ & $<.01$ \\
\hline
\end{tabular}

$P A$, Pulmonary artery; $\mathrm{Cl}$, confidence interval. Variables not associated with mortality in the univariable or multivariable analyses included age at surgery, gender, presence of ventricular septal defect, aortic arch obstruction, Taussig-Bing type of double-outlet right ventricle, balloon atrial septostomy, Lecompte maneuver, delayed sternal closure, mechanical ventilation time, length of stay in the cardiac ICU, hospital stay, and reintervention.

* Variables having a $P<.2$ in the univariable analysis, and entered into the backward stepwise multivariable logistic regression model.

† Side-by-side compared to other positions.

$\ddagger$ Single right ostium with the left main artery posterior to the PA compared to other coronary artery patterns.

TGA and intact ventricular septum and a single CA and $41 \%$ for patients with TGA and associated VSD, in the $31 / 2$ years immediately preceding the close of the series, the mortality of 6 consecutive neonates with single CA was $0 \%$. For both institutions this remarkable improvement was attributed mainly to increased surgical experience. The specific technical issues, which are relevant to the management of the single CA pattern including appropriate cardiopulmonary bypass technique, have been described in detail recently. ${ }^{15}$

CA pattern as a risk factor for increased mortality has been demonstrated in numerous studies. ${ }^{1,3,5,16,17} \mathrm{~A}$ single right ostium with a retropulmonary course of the main or circumflex artery was the most common single CA pattern in our study and involved the highest risk of early mortality. Five of the 7 patients in our series died early, all of whom had a single right ostium with a retropulmonary course of the left CA, and autopsies revealed that 4 of the early deaths were due to coronary malperfusion. This is consistent with an article published by Kirklin and associates, ${ }^{4}$ reporting the ongoing results of the Congenital Heart Surgeons Society study of transposition. The ASO was performed in 513 neonates, and CA anatomy emerged as a risk factor. Origin of the left CA or only the left anterior descending or circumflex CA from the leftward posterior facing sinus (sinus 2) was a risk factor for early death. Reporting single institution experiences, both Daebritz, ${ }^{3}$ Tamisier, ${ }^{13}$ and their associates found a single right CA as a risk factor for early mortality in other large series.
The side-by-side position of the great arteries had an approximately 6-fold higher risk for mortality than did the other relationships in our series. Shukla, Freedom, and Black, ${ }^{14}$ focusing on TGA and single CA pattern, found side-by-side position of the great arteries to be common, but they did not state numbers. For all CA patterns, a side-byside position of the great arteries was a risk factor for mortality in 2 articles published recently. ${ }^{3-6}$

Four of the 7 deaths that occurred at our institution were within 30 days of surgery and the other deaths were within 7 months of ASO. There have been no deaths beyond 7 months. Mortality decreases with time after ASO, and this reduction has been reported from many institutions. ${ }^{3,4,12,13,18}$

Relief of right ventricular and/or PA stenosis was the most common indication for reintervention after ASO in various reports. ${ }^{1,3,12,19,20}$ In a multi-institutional report from the Congenital Heart Surgeons Society published in 1988, Norwood and coworkers ${ }^{19}$ demonstrated that most patients required relief of right ventricular outflow tract obstruction within 1 year after ASO. This finding has also been shown more recently. ${ }^{1,3,20}$ In our series we found that right ventricular outflow tract obstruction was the most common indication for reintervention. Most of the reoperations were performed within 1 year after ASO. Reintervention rates, particularly for right ventricular outflow tract obstruction, were higher in patients with a single left $\mathrm{CA}$ in whom the right CA passed anterior to the aorta than in other single CA patterns. As this pattern is often associated with a side-by- 


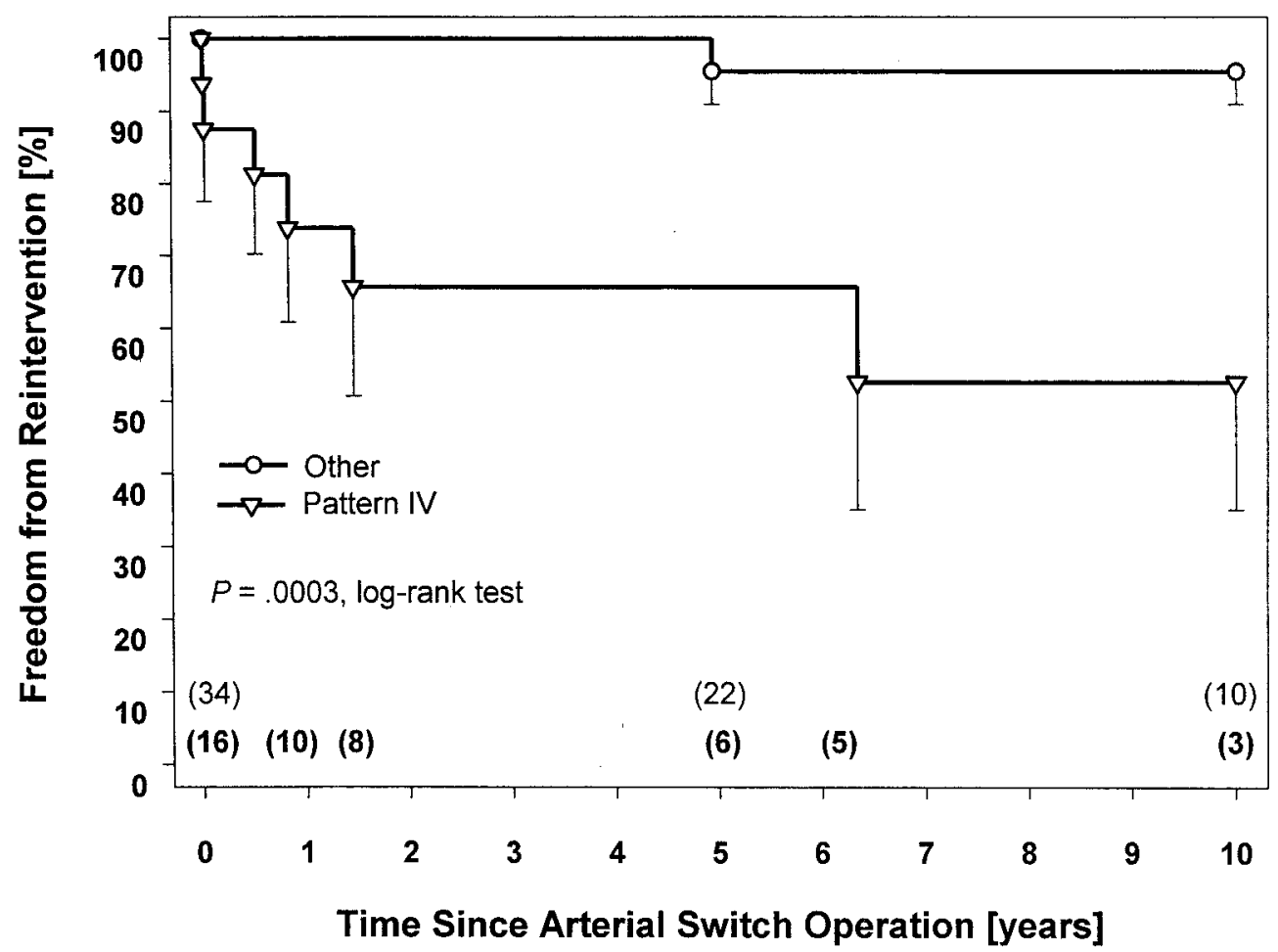

Figure 5. Kaplan-Meier estimated freedom from reintervention according to single CA pattern $(P=.0003$, log-rank test) for 10 years after ASO. Error bars indicate the lower $95 \% \mathrm{Cl}$. Numbers of patients at risk shown in parentheses in boldface represent patients having a single left ostium with the right coronary artery anterior to the aorta (see Figure 1, IV compared with patients with other CA patterns shown in italics.

TABLE 4. Risk factors for reintervention

\begin{tabular}{|c|c|c|c|c|}
\hline \multirow[b]{2}{*}{ Variable } & \multirow{2}{*}{$\frac{\text { Univariable* }^{*}}{P \text { value }}$} & \multicolumn{3}{|c|}{ Multivariable Cox regression model } \\
\hline & & Risk ratio & $95 \% \mathrm{Cl}$ & $P$ value \\
\hline Age at surgery, days & .04 & & & .12 \\
\hline Taussig-Bing DORV & .18 & & & .34 \\
\hline Position of the great arteries & .06 & & & .2 \\
\hline Coronary artery patternt & .02 & 16.5 & $2.8-38.9$ & $<.001$ \\
\hline Year of surgery & .05 & & & .1 \\
\hline
\end{tabular}

DORV, Double-outlet right ventricle; $\mathrm{Cl}$, confidence interval.

* Variables having a $P<.2$ in the univariable analysis, and entered into the backward stepwise multivariable Cox Regression model.

† Single left ostium with the right coronary artery anterior to the aorta compared to other coronary artery patterns.

Variables not associated with reintervention in the univariable or multivariable analyses included gender, birth weight, presence of a ventricular septal defect, aortic arch obstruction, prior pulmonary artery banding, balloon atrial septostomy, Lecompte maneuver, revision of coronary anastomosis, delayed sternal closure, mechanical ventilation time, cross clamp time, total pump time, length of stay in the cardiac ICU, and hospital stay.

side position of the great arteries, there might be a higher risk of tension on the PA anastomosis. Norwood and colleagues ${ }^{19}$ hypothesized that the Lecompte maneuver might predispose to right ventricular outflow tract obstruction. In our series a Lecompte maneuver was performed in all patients with reintervention, but the maneuver statistically did not prove to be a risk factor for reintervention.

Since the introduction of the ASO,${ }^{21}$ late CA problems after the procedure have been described. Bonnet and associates $^{22}$ found occlusion or stenosis of the CAs in 5 of 58 patients who underwent selective coronary angiography. In a subsequent report from the same group, ${ }^{23}$ a total of 12 coronary occlusions were identified in 165 children who underwent selective coronary angiography at an average age of approximately 6 years. In a report by Tanel and coworkers, ${ }^{24} 13(3 \%)$ patients were identified as having previously 
unsuspected CA abnormalities among 366 patients who underwent postoperative catheterization after ASO. One of these 13 patients, who was asymptomatic, had a single right CA pattern with normal function. Catheterization showed a small fistula from the right $\mathrm{CA}$ to the PA. One patient died suddenly 3 years after surgery, 1 was lost to follow-up, and the other 10 were alive without symptoms for several years after surgery.

In our study one 13-year old boy with a single right CA had evidence of myocardial ischemia. The parents reported that their child had excellent exercise tolerance, and echocardiography revealed normal function and structure. To receive the school's permission to participate in sports, a myocardial perfusion scan was performed. The scan demonstrated severe involvement in the circumflex and right CA distribution. Ischemia was detected throughout the base of the heart, posteriorly, in all but the inferior quadrant. Cardiac catheterization subsequently demonstrated hypoplasia of the left anterior descending CA but no evidence of obstruction at the site of CA reimplantation. Nevertheless, we do think that, when no clinical signs of ischemia are present, an annual echocardiographic study should be sufficient for patients after ASO with usual as well as with a single CA pattern.

\section{Conclusion}

In the 1980s the ASO with a single CA pattern, especially a single right ostium with the left main CA posterior to the PA, carried an increased risk of mortality. In the current era, ASO with a single CA ostium can be performed safely irrespective of the single CA anatomy. However, the risk of late reintervention is higher for patients having a single left ostium with the right $\mathrm{CA}$ anterior to the aorta.

Beside the authors (P.dN., J.E.M., R.A.J.), the following surgeons undertook operations described in this series: Aldo Castaneda, Frank Hanley, Redmond Burke, and Emile Bacha. We thank Peter Lang, MD, for his support and advice.

\section{References}

1. Serraf A, Lacour-Gayet F, Bruniaux J, Touchot A, Losay J, Comas J, et al. Anatomic correction of transposition of the great arteries in neonates. J Am Coll Cardiol. 1993;22:193-200.

2. Yamaguchi M, Hosokawa Y, Imai Y, Kurosawa H, Yasui H, Yagihara $\mathrm{T}$, et al. Early and midterm results of the arterial switch operation for transposition of the great arteries in Japan [see comments]. J Thorac Cardiovasc Surg. 1990;100:261-9.

3. Daebritz SH, Nollert G, Sachweh JS, Engelhardt W, von Bernuth G, Messmer BJ. Anatomical risk factors for mortality and cardiac morbidity after arterial switch operation. Ann Thorac Surg. 2000;69: 1880-6.
4. Kirklin JW, Blackstone EH, Tchervenkov CI, Castaneda AR. Clinical outcomes after the arterial switch operation for transposition: patient, support, procedural, and institutional risk factors. Congenital Heart Surgeons Society [see comments]. Circulation. 1992;86:1501-15.

5. Wernovsky G, Mayer JE, Jr, Jonas RA, Hanley FL, Blackstone EH, Kirklin JW, et al. Factors influencing early and late outcome of the arterial switch operation for transposition of the great arteries. $J$ Thorac Cardiovasc Surg. 1995;109:289-301.

6. Blume ED, Altmann K, Mayer JE, Colan SD, Gauvreau K, Geva T. Evolution of risk factors influencing early mortality of the arterial switch operation [see comments]. J Am Coll Cardiol. 1999;33:1702-9.

7. Kaplan EL, Meier P. Nonparametric estimation from incomplete observation. J Am Stat Assoc. 1958;53:457-81.

8. Hosmer DW, Lemeshow S. Applied logistic regression. 2nd ed. New York: John Wiley; 2000. p. 47-69.

9. Cox DR. Regression models and life-tables (with discussion). J R Stat Soc Series B. 1972;34:187-220.

10. Van Praagh R. What is the Taussig-Bing malformation? Circulation. 1968:38:445-9.

11. Castaneda AR, Trusler GA, Paul MH, Blackstone EH, Kirklin JW. The early results of treatment of simple transposition in the current era. J Thorac Cardiovasc Surg. 1988;95:14-28.

12. Wernovsky G, Sanders SP. Coronary artery anatomy and transposition of the great arteries. Coron Artery Dis. 1993;4:148-57.

13. Tamisier D, Ouaknine R, Pouard P, Mauriat P, Lefebvre D, Sidi D, et al. Neonatal arterial switch operation: coronary artery patterns and coronary events. Eur J Cardiothorac Surg. 1997;11:810-7.

14. Shukla V, Freedom RM, Black MD. Single coronary artery and complete transposition of the great arteries: A technical challenge resolved? Ann Thorac Surg. 2000;69:568-71.

15. Scheule AM, Jonas RA. Management of transposition of the great arteries with single coronary artery. In: Williams WG, editor. Pediatric cardiac surgery annual. Philadelphia: WB Saunders; 2001.

16. Mayer JE Jr, Sanders SP, Jonas RA, Castaneda AR, Wernovsky G. Coronary artery pattern and outcome of arterial switch operation for transposition of the great arteries. Circulation. 1990;82(Suppl):IV139-45.

17. Day RW, Laks H, Drinkwater DC. The influence of coronary anatomy on the arterial switch operation in neonates. J Thorac Cardiovasc Surg. 1992;104:706-12.

18. Planche C, Bruniaux J, Lacour-Gayet F, Kachaner J, Binet JP, Sidi D, et al. Switch operation for transposition of the great arteries in neonates: a study of 120 patients. J Thorac Cardiovasc Surg. 1988;96: 354-63.

19. Norwood WI, Dobell AR, Freed MD, Kirklin JW, Blackstone EH. Intermediate results of the arterial switch repair: a 20-institution study. J Thorac Cardiovasc Surg. 1988;96:854-63.

20. Haas F, Wottke M, Poppert H, Meisner H. Long-term survival and functional follow-up in patients after the arterial switch operation. Ann Thorac Surg. 1999;68:1692-7.

21. Jatene AD, Fontes VF, Paulista PP, Souza LC, Neger F, Galantier M, et al. Anatomic correction of transposition of the great vessels. J Thorac Cardiovasc Surg. 1976;72:364-70.

22. Bonnet D, Bonhoeffer P, Piechaud JF, Aggoun Y, Sidi D, Planche C, et al. Long-term fate of the coronary arteries after the arterial switch operation in newborns with transposition of the great arteries. Heart. 1996;76:274-9.

23. Bonhoeffer P, Bonnet D, Piechaud JF, Stumper O, Aggoun Y, Villain E, et al. Coronary artery obstruction after the arterial switch operation for transposition of the great arteries in newborns. $J$ Am Coll Cardiol. 1997;29:202-6.

24. Tanel RE, Wernovsky G, Landzberg MJ, Perry SB, Burke RP. Coronary artery abnormalities detected at cardiac catheterization following the arterial switch operation for transposition of the great arteries. Am J Cardiol. 1995;76:153-7. 